\title{
Pembuatan Video Cinematic Promosi Pada Perumahan Grand Mutiara Village
}

\author{
Yahya Suherman ${ }^{\mathrm{a} *}$, Rahmat Gunawan ${ }^{\mathrm{b}}$, Shafira Ramadhanti Roswandi ${ }^{\mathrm{c}}$ \\ ${ }^{a}$ STMIK Rosma, Jl. Kertabumi No. 62, Karawang 41311, Indonesia \\ *Corresponding author: vahya.suherman@dosen.rosma.ac.id
}

\begin{abstract}
Promotional activities are currently very important to introduce a product or service to attract customers. PT Elang Buana is one of the housing developers, one of which is named Grand Mutiara Village Housing which is located on Jl. HS. Ronggo Waluyo, Puseurjaya, Kec. Telukjambe Timur, Karawang Regency. For the promotion of Grand Mutiara Village, they still use internet promotion media in the form of uploading some photos on Facebook, holding open tables if there are certain events and in certain locations, in collaboration with various property agents. So that the media promotion is not maximized. The current problem is the need for promotional media that can maximize promotion. So it is necessary to have promotional videos through social media and YouTube, so that theycan increase product sales. This study uses a qualitative approach with three data collection techniques, namely observation, interviews, and literature study. The supporting hardware for making this promotional video is the Sony A6000 kit 60 -50mm Camera and its supporting software, Adobe Premiere Pro. The results of this study are in the form of promotional video media for Grand Mutiara Village which is expected to attract customers' interest in the products offered.
\end{abstract}

Keywords : Promotional Video, Housing, Social Media

\begin{abstract}
Abstrak
Kegiatan promosi saat ini sangat penting untuk memperkenalkan suatu produk atau jasa guna menarik min at customer. PT Elang Buana merupakan salah satu pengembang perumahan yang salah satuny a diberi nama Perumahan Grand Mutiara Village yang berada di Jl. HS.Ronggo Waluyo, Puseurjaya, Kec. Telukjambe Timur, Kabu paten Karawang. Untuk promosi Grand Mutiara Village masih menggunakan media promosi internet yakni berupa mengupload beberapa foto di facebook, dilakukan nya open table jika ada event tertentu dan di lokasi tertentu, bekerja sama dengan berbagai beberapa agen property. Sehingga media promosinya dirasa belum maksimal. Permasalahan saat ini dibutuhkanny a media promosi yang dapat memaksimalkan promosi. Maka diperlukan adanya video promosi melalui social media dan youtube, sehingga dapat meningkatkan penjualan produk. Penelitian ini menggunakan pendekatan kualitatif dengan tiga teknik pengumpulan data yaitu observasi, wawancara, dan studi literature. Hardware pendukung pada pembuatan video promosi ini yaitu Camera Sony A6000 kit 60-50mm dan software pendukung nya yaitu Adobe Premiere Pro. Hasil dari penelitian ini berupa media video promosi Grand Mutiara Village yang diharapkan dapat menarik minat customer akan produk yang ditawarkan.
\end{abstract}

Keywords : Video Promosi, Perumahan, Social Media

\section{Pendahuluan}

Perkembangan zaman merupakan suatu hal yang tidak bisa kita hindari sehingga mau tidak mau kita harus siap menghadapinya. Salah satu perkembangan zaman yang paling terasa saat ini adalah perkembangan di bidang promosi. Pada hakikatnya promosi adalah suatu bentuk komunikasi pemasaran untuk menyebarkan informasi, me mengaruhi, membujuk, dan atau mengingat agar pasar sasaran atas perusahaan dan produknya agar bersedia menerima, membeli dan loyal pada produk yang ditawarkan oleh perusahaan yang bersangkutan. 
PT Elang Buana merupakan salah satu pengembang perumahan yang salah satuny a diberi nama Perumahan Grand Mutiara Village dimana perumahan ini memiliki keunggulan yaitu harga yang terjangkau, de sain bangunan yang menarik, lokasi yang strategis, dan fasilitas-fasilitas yang lengkap. Berlokasi di Jl. HS.Ronggo Waluyo, Puseurjaya, Kec. Telukjambe Timur, Kabupaten Karawang.

Grand Mutiara Village saat ini masih menggunakan media promosi internet yakni berupa mengupload beberapa foto di facebook, dilakukan nya open table jika ada event tertentu dan di lokasi tertentu, bekerja sama dengan berbagai beberapa agen property yang menurut penulis masih kurang untuk dijadikan sebagai media promosi. Video promosi adalah media komunikasi secara visual, yang berisi pesan yang dapat dilihat audiensi dan tentu saja berkaitan dengan hal komersial. Untuk itu diperlukan adanya pembuatan video promosi guna mempermak simalk an promosi agar penjualan produk semakin meningkat. Beberapa penelitian terdahulu yang merancang video promosi seperti yang dilakukan oleh (Sunarya et al., 2021), (Panegak \& Kusumandyoko, 2021), (Pratiwi et al., 2020), (Fajar et al., 2017), (Veza \& Safira, 2020). Dengan banyaknya penelitian yang melakuka perancangan vid eo promosi tersebut, maka penulis tertarik untuk merancang sebuah video promosi pada PT. Elang Buana dalam rangka meningkatkan kegiatan promosi perumahan Grand Mutiara Village agar lebih menarik perhatian masyarakat.

\section{Tinjauan Pustaka}

2.1. Video

Video adalah gambar hidup (bergerak; motion), proses perekamannya, dan penayanganny a y ang tentuny a melibatkan teknologi (Tarigan et al., 2020).

\subsection{Promosi}

Promosi merupakan kegiatan yang ditujukan untuk mempengaruhi konsumen agar konsumen dapat menjadi kenal akan produk yang ditawarkan oleh perusahaan kepada konsumen, yang kemudian konsumen dapat menjadi senang lalu akan menggunakan produk tersebut (Listyawati, 2016)(Garaika \& Feriyan, 2019).

\subsection{Video Promosi}

Video promosi adalah sebuah media yang digunakan untuk mempromosikan sesuatu yang dimilki, dengan durasi yang singkat dan menarik sehingga mampu menarik minat masyarakat luas termasuk konsumen (Nurani et al., 2020). Sedangkan menurut Terence (2003) Video Promosi adalah bentuk penayangan informasi yang bersifat audio visual sehingga menjadi kunci mengenai suatu merek atau membagikan informasi kepada pelanggan dan konsumen akhir (Wari \& Ardoni, 2018).

\section{4. $\quad$ Storyboard}

Storyboard adalah bahan visual dari semula berbentuk bahasa tulisan menjadi bahasa gambar atau bahasa visual yang filmis. keseluruhan, sehingga menggambarkan suatu cerita (Nurdin et al., 2020). Storyboard merupakan visualisasi ide dari aplikasi yang akan dibangun, sehingga dapat me mberikan gambaran dari aplikasi yang akan dihasilkan. Storyboard dapat dikatakan juga visual script yang akan dijadikan outline dari sebuah proyek, ditampilkan shot by shot yang biasa disebut dengan istilah scene (Kunto et al., 2021).

\section{Metode}

Metode penelitian yang digunakan dalam perancangan video promosi Perumah an Grand Mutiara Village ini adalah metode kualitatif. Pendekatan kualitatif sebagai prosedur penelitian yang menghasilkan data deskriptif berupa kata-kata tertulis atau lisan dari orang-orang dan perilaku yang dapat diamati (Rusdi, 2019). Metode penelitian kualitatif juga merupakan penelitian yang berusaha untuk mendiskrisikan hasil pengujian dengan mengintepretasikan data (Setiyani, 2019). Metode kualitatif dipilih untuk dapat menangkap latar ilmiah dari suatu objek penelitian dan kajian teori hanya sekedar sebagai pedoman. Setelah itu dari pengumpulan data-data akan di klasifikasikan menjadi suatu data, yang nantinya akan bisa menjadi sebuah konsep ide visual dari penciptaan. Teknik pengu mpulan data menggunakan 3 teknik yaitu :

a. Observasi

Observasi di lakukan secara menyeluruh di kawasan Grand Mutiara Village, Pada saat observasi mengenai produk dan fasilitas-fasilitas yang berada di Grand Mutiara Village.

b. Wawancara

Wawancara dilakukan kepada mba Nency selaku in house di kantor pemasaran Grand Mutiara Village. Penulis 
mencari data tentang sejarah Grand Mutiara Village, hasil produksi dan informasi mengenai Grand Mutiara Village.

\section{c. Studi literatur}

Studi Literatur mengambil teori teori yang mendukung proses pembuatan video promosi Grand Mutiara Village seperti penelitian terdahulu, buku jurnal dan artikel yang diperoleh dari website.

Ada pula Rancangan Analisis Data yang dibuat seperti berikut:

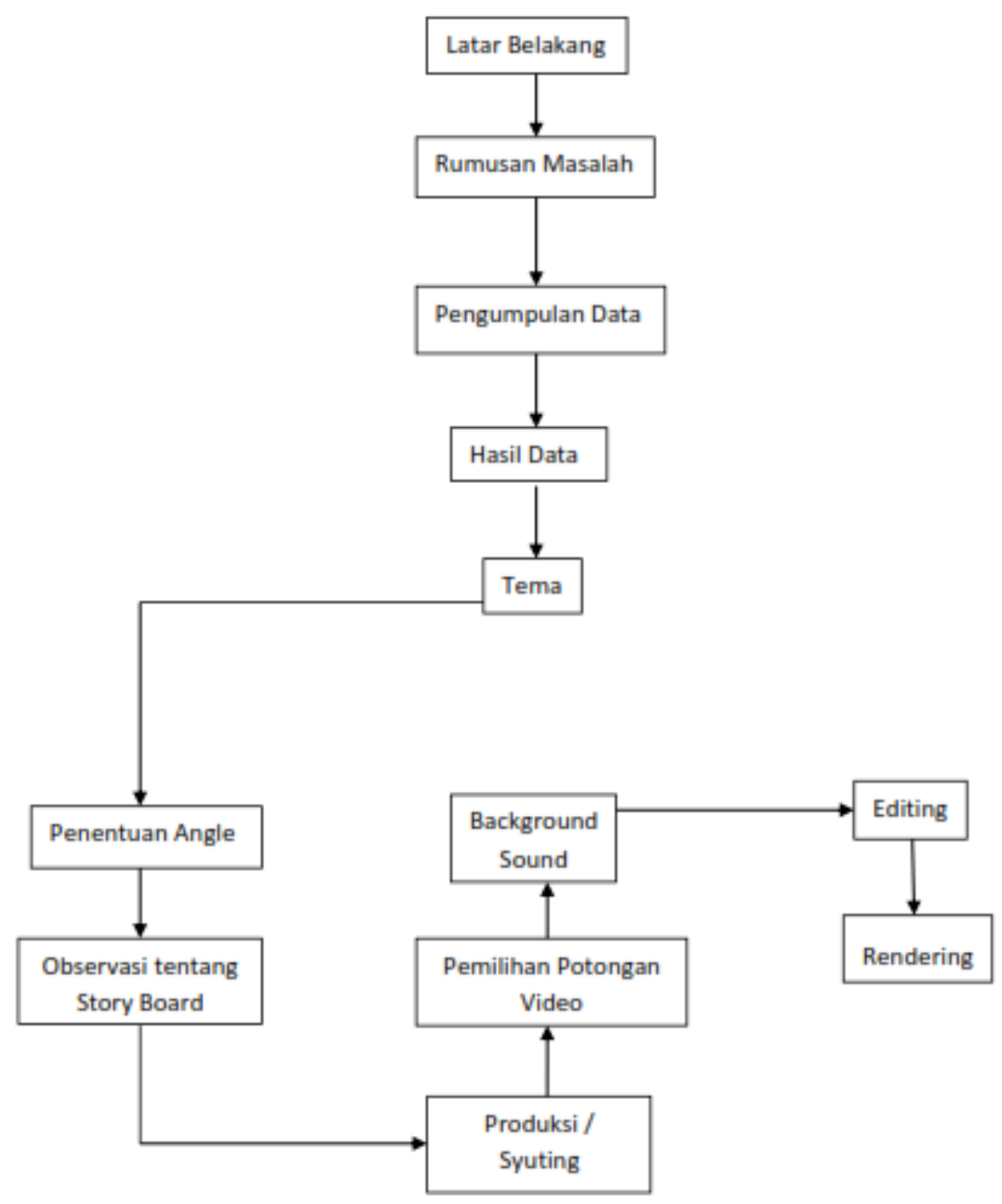

Gambar 1. Rancangan Analisis Data

\section{Hasil dan Pembahasan}

\subsection{Konsep Dasar Perancangan}

Apa yang akan dibuat oleh penulis disini adalah sebuah video promosi bersifat komersial. Sebuah video promosi untuk sebuah Perumahan di daerah Karawang, dengan menggunakan teknik cin ematic. Video ini ditunjukan untuk masyarakat kelas menengah untuk range usia 21 - 55 (untuk Karyawan), karena perkiraan pada usia tersebut merupakan sebuah momen dimana mereka mayoritas memiliki perkerjaan dan penghasilan tetap. Memiliki rumah pribadi merupakan impian banyak orang, terutama bagi merek a y ang sudah bekerja dan berpenghasilan tetap. Konsep ini dibuat setelah melakukan observasi data, bahwa masyarakat di Indonesia lebih cepat menerima pesan dalam bentuk video. Hanya dengan berdurasi selama satu menit, diharapkan semoga video promosi ini dapat dengan mudah diterima dan mu dah diresap pesan informasinya oleh masyarakat.

\section{2. $\quad$ Storyboard}

Storyboard adalah tahap awal dalam perancangan video promosi Grand Mutiara Village ini. Berikut rangkaian story board untuk perancangan video promosi Grand Mutiara Village : 
Tabel 1. Storyboard

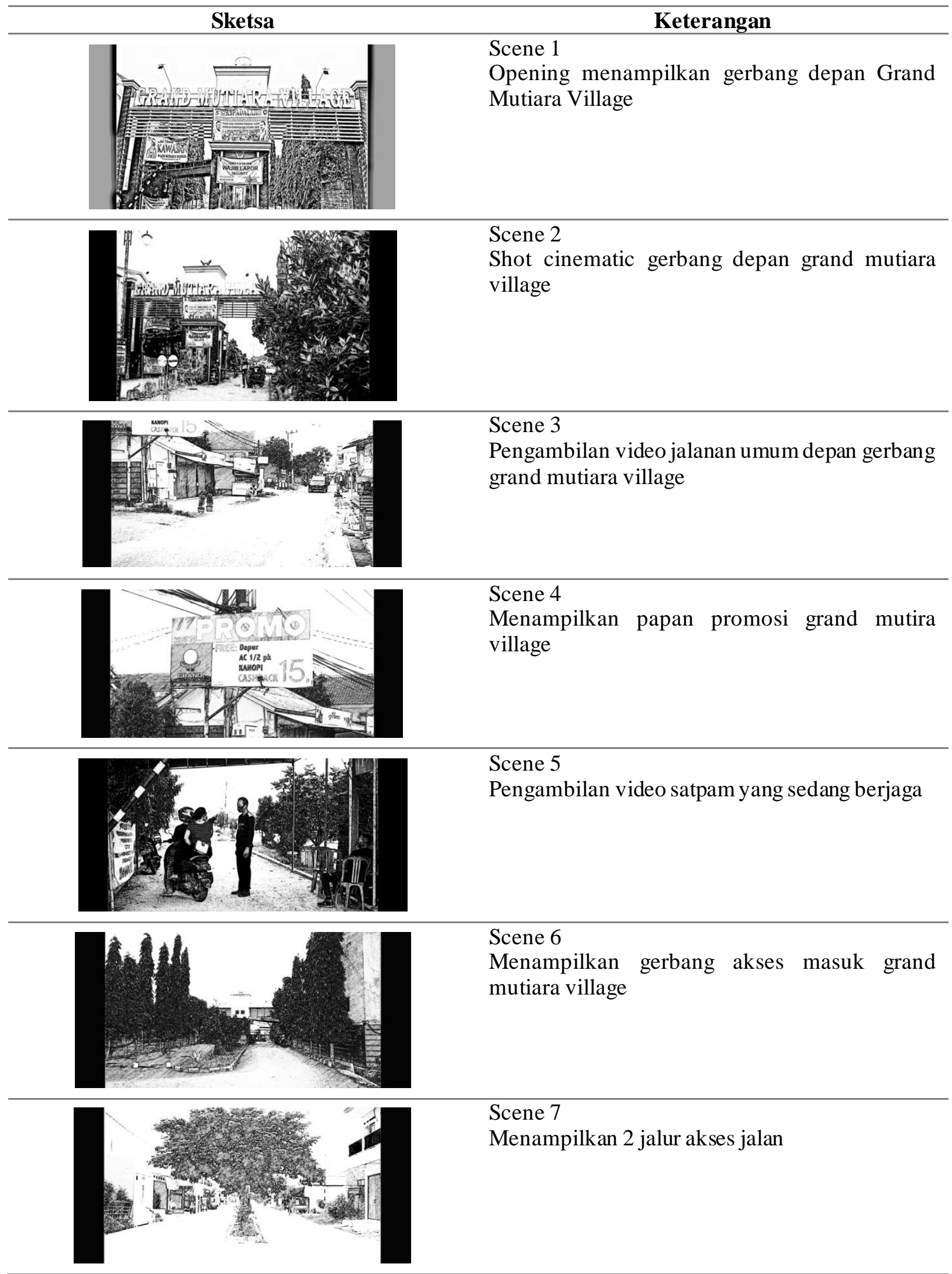




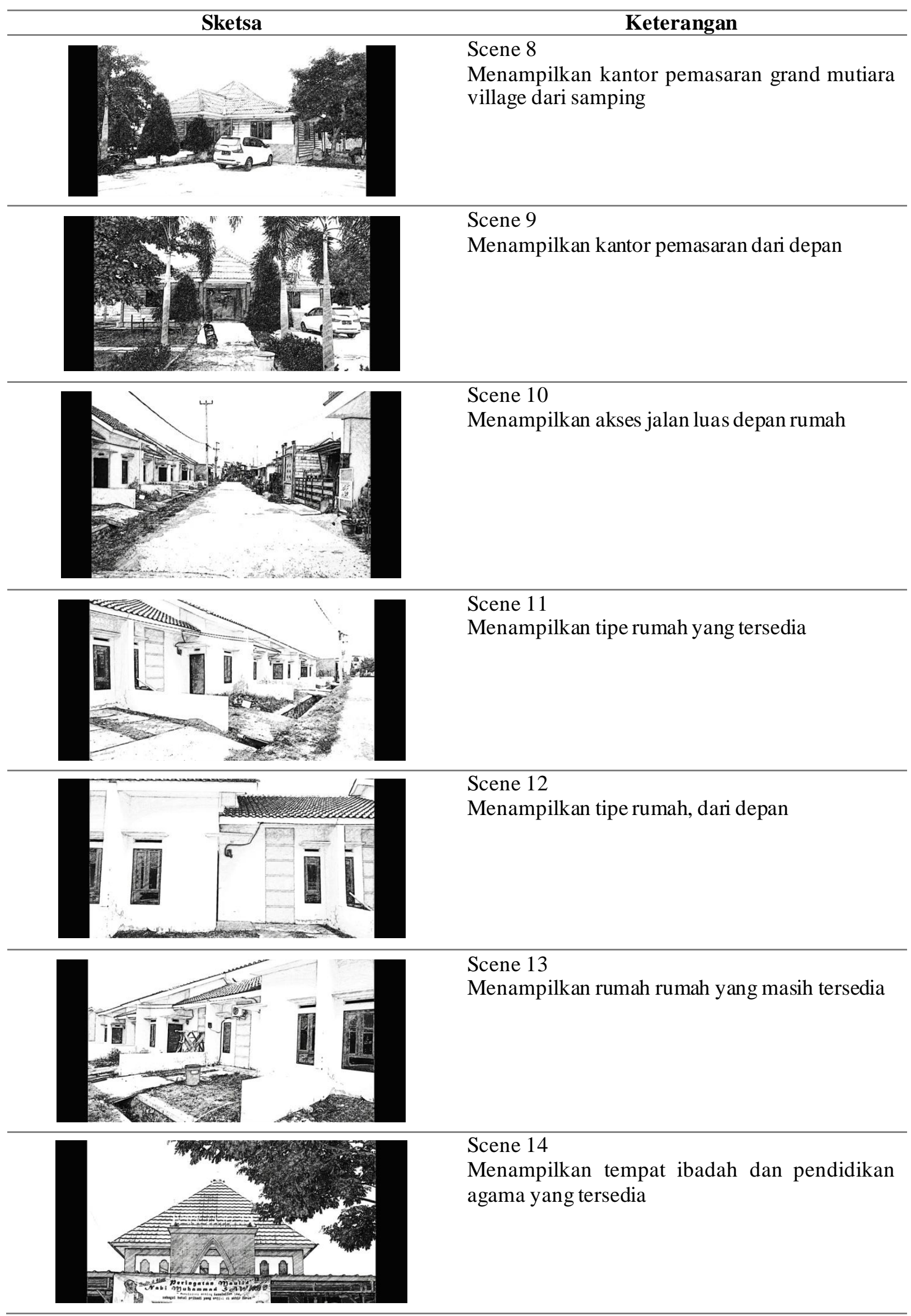




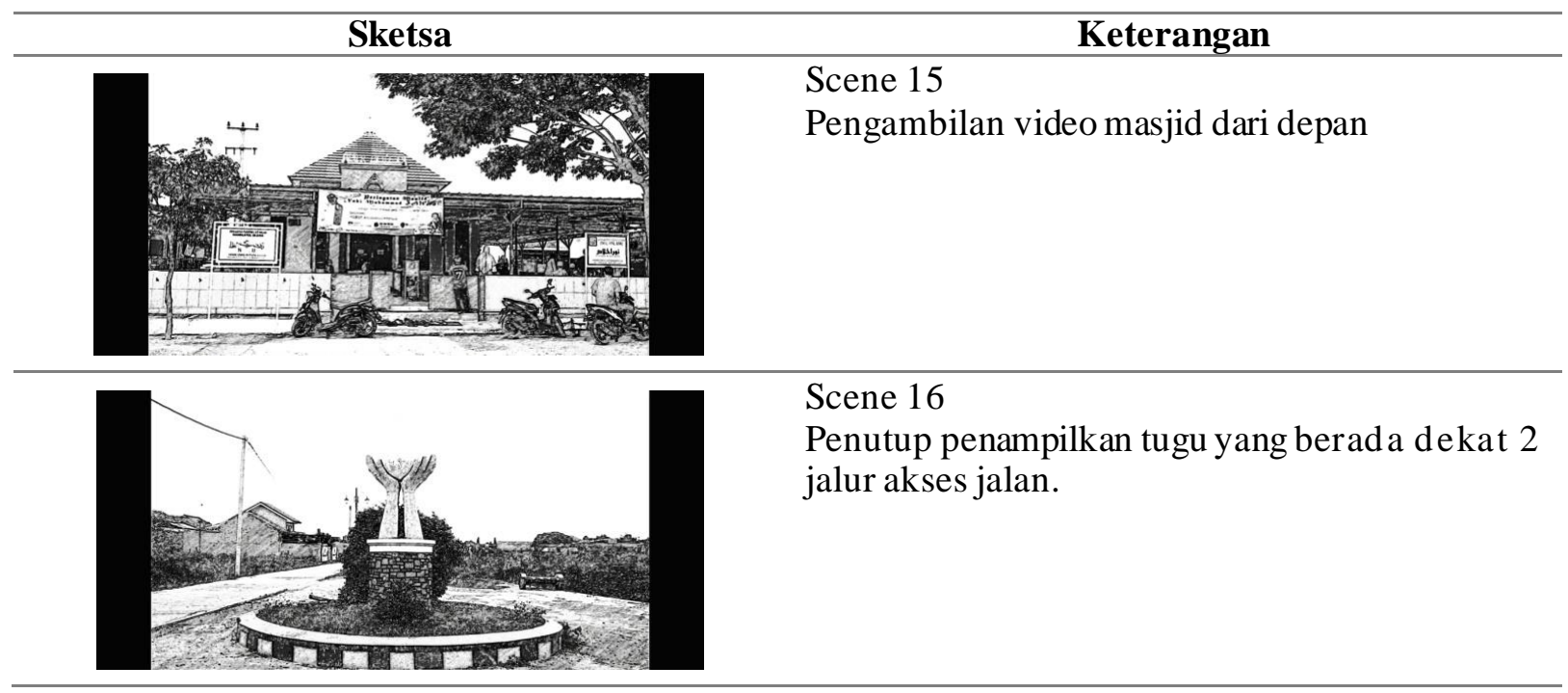

\subsection{Final Video Promosi}

Final desain yaitu sebuah tahap akhir dimana dalam proses perancangan karya yang pada awalnya sebuah sketsa gambar dan di realisasikan. Pada tahap ini pengaplikasian dilakukan dengan cara komputerisasi ter lebih dahulu menggunakan software yang diperlukan. Berikut merupakan cuplikan gambar dari Final Video Promosi Grand Mutiara Village :

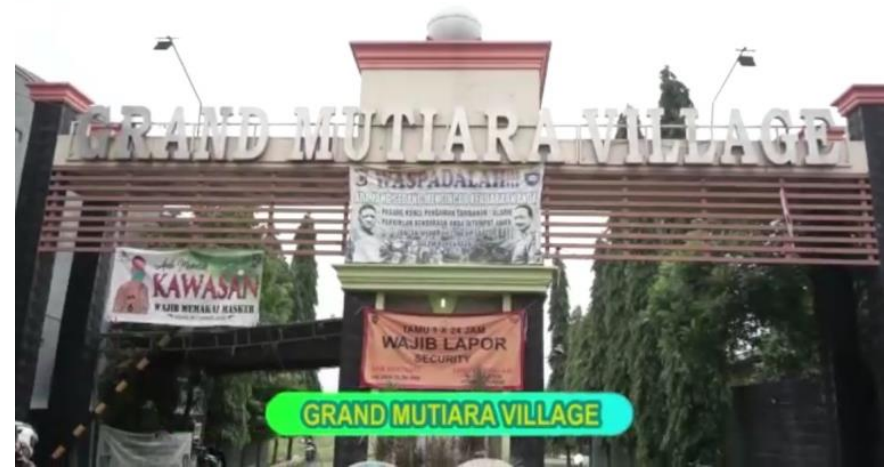

Gambar 2. Final video promosi

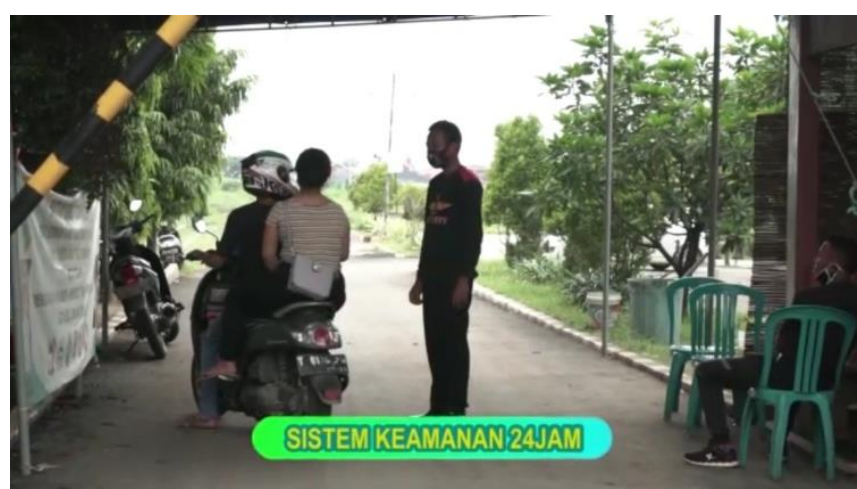

Gambar 3. Final Video Promosi 


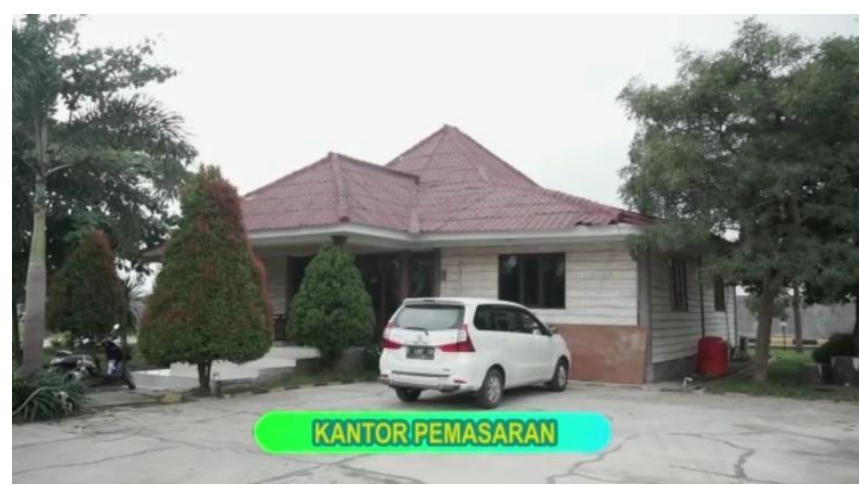

Gambar 3. Final Video Promosi

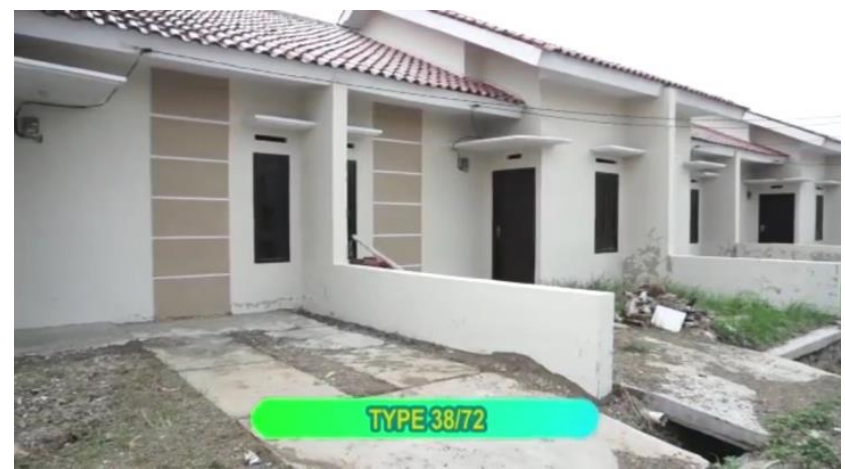

Gambar 4. Final Video Promosi

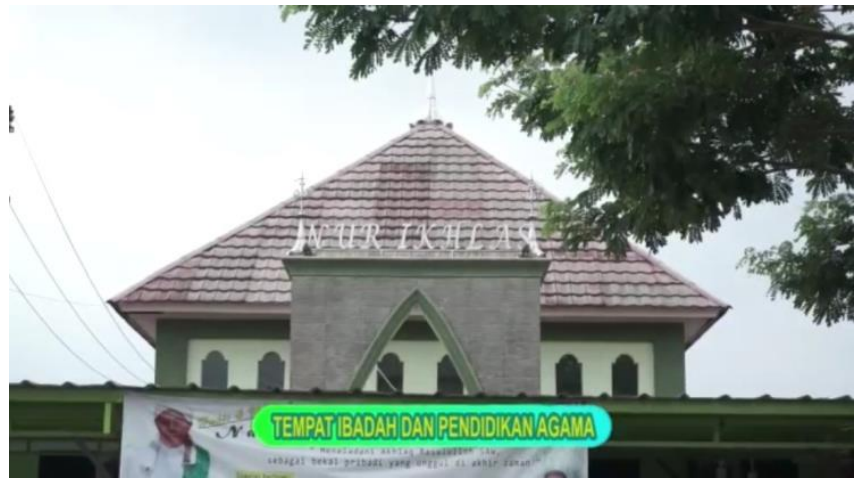

Gambar 5. Final Video Promosi

\section{Kesimpulan \& Saran}

\subsection{Kesimpulan}

Untuk mempermaksimalkan promosi Grand Mutiara Village perlu dilakukan perancangan sebuah media promosi yang dapat meningkatkan penjualan produk dan menarik customer. Video promosi yang dipakai akan difokuskan penyebarannya melalui media sosial. Karena media sosial sangat efisien dan mudah untuk diakses para audiens. Konsep dari perancangan adalah untuk menciptakan sebuah video promosi yang menarik untuk calon konsumen dan menjelaskan produk dari Grand Mutiara Village. Video promosi ditunjukan untuk masyarakat kelas menengah untuk range usia 21 - 55 (untuk Karyawan), karena perkiraan pada usia tersebut merupakan sebuah momen dimana mereka mayoritas memiliki perkerja an dan penghasilan tetap. Video Promosi dibuat karena menurunnya jumlah penjualan produk terutama pada saat ini karena terjadinya sedang Pandemi Covid-19. Dalam perancangan video promosi penulis menggunakan software Adobe Premier Pro dan kamera Sony A6000 Kit 60-50mm. Media promosi berupa Video Promosi bisa diterapkan dan bermanfaat bagi Grand Mutiara Village.

\subsection{Saran}

Untuk teknik pemasaran selain dilakukan dengan cara open table dibeberapa lokasi, sebaiknya diperluas lagi yaitu melalui social media seperti Facebook, Instagram, dan Youtube. Penulis merek omen pengambilan foto atau video untuk dipromosikan di Facebook, Instagram atau Youtube haru s dari angle of 
view (sudut pandang) yang bagus dan menarik agar customer tertarik untuk membeli produk yang dijual. Dan penulis menyadari masih banyak kekurangan dalam perancangan video promosi ini. Oleh karena itu disarankan agar melakukan perbaikan pengambilan gambar dengan menggunakan alat pengambil gambar (kamera) yang lebih memadai juga dengan tenaga ahli yang lebih piawai.

\section{References}

Fajar, I., Kamal, N., \& Faisal, D. (2017). PERANCANGAN VIDEO PROMOSI CAFE OMBEWOK. Jurnal Desain Komunikasi Visual, $\quad 2(1), \quad 1-10$. http://linkinghub.elsevier.com/retrieve/pii/S0167273817305726\%0Ahttp://dx.doi.org/10.1038/s41467-017-017721\%0Ahttp://www.ing.unitn.it/ luttero/laboratoriomateriali/RietveldRefinements.pdf\%0Ahttp://www.intechopen .c o $\mathrm{m} /$ books/spectroscopic-analyses-developments-an

Garaika, G., \& Feriyan, W. (2019). Promosi Dan Pengaruhnya Terhadap Terhadap Animo Calon Mahasiswa Baru Dalam Memilih Perguruan Tinggi Swasta. Jurnal AKTUAL, 16(1), 21.https://doi.org/10.47232/aktual.v 16i1.3

Kunto, I., Ariani, D., Widyaningrum, R., \& Syahyani, R. (2021). Ragam Storyboard Untuk Produksi Media Pembelajaran. Jurnal Pembelajaran Inovatif, 4(1), 108-120. https://doi.org/10.21009/jpi.041.14

Listyawati, I. H. (2016). Peran Penting Promosi dan Desain Produk Dalam Membangun Minat Beli Konsumen. Jbma, III(1), 62-70.

Nurani, S. A., Jayawinangun, R., \& Satriani, I. (2020). ANALISIS PENDEKATAN MARKETING PUBLIC RELATIONS DALAM PENGEMBANGAN PROMOSI PARIWISATA DI KOTA BOGOR. Jurnal Penelitian Sosial Dan Ilmu Komunikasi, 4(2), 14114-14122. https://journal.unpak.ac.id/index.php/apik\%0AVolume

Nurdin, Noviana, Munar, \& Taufiq. (2020). Cd Interaktif Pengenalan Sejarah Kebudayaan Islam Pada Madrasah Ibtidaiyah. Jurnal Teknologi Terapan and Sains $4.0, \quad$. https://doi.org/https://doi.org/10.1976/tts\%204.0.v1i2.3251

Panegak, M. S., \& Kusumandyoko, T. C. (2021). PERANCANGAN VIDEO PROMOSI BATIK DESA SENDANGDUWUR KABUPATEN LAMONGAN. Jurnal Barik, 2(3), 229-242.

Pratiwi, K. N. K., Suryana, J., \& Witari, N. N. S. (2020). PERANCANGAN VIDEO PROMOSI PERAHU WIS ATA DI PANTAI PENIMBANGAN, SINGARAJA, BALI. Jurnal Pendidikan Seni Rupa Undiksha, 10(2), 103-112.

Rusdi, M. (2019). Strategi Pemasaran untuk Meningkatkan Volume Penjualan pada Perusahaan Genting UD. Berkah Jaya. Jurnal Studi Manajemen Dan Bisnis, 6(2), 83-88. https://doi.org/10.21107/jsmb.v6i2.6686

Setiyani, L. (2019). Pengujian Sistem Informasi Inventory Pada Perusahaan Distributor Farmasi Menggu nakan Metode Black Box Testing. Techno Xplore: Jurnal Ilmu Komputer Dan Teknologi Informasi, 4(1), 1-9. https://doi.org/10.36805/technoxplore.v4i1.539

Sunarya, L., Purbayani, A. D., \& Handayani, N. (2021). Media Video Promosi Pada Roofpark Cafe \& Restaurant Pucak Bogor Jawa Barat. Technomedia Journal, 5(2), 220-234. https://doi.org/10.33050/tmj.v5i2.1448

Tarigan, R. O., Hanim, W., \& Wirasati, R. M. K. (2020). Video Simulasi Pengembangan Video Simulasi Konseling Teknik Dispute Cognitive Untuk Meningkatkan Resiliensi. Insight: Jurnal Bimbingan Dan Konseling, 9(1), 01-08. https://doi.org/10.21009/jpi.031.01

Veza, O., \& Safira, E. (2020). Perancangan Video Iklan Promosi Di Perusahaan Kaos Menggunakan Metode Multimedia Development Life Cycle. Engineering And Technology International Journal, 2(3), 9-19.

Wari, N. P., \& Ardoni. (2018). Pembuatan Video Promosi Perpustakaan Layanan Anak di Dinas Kearsipan dan Perpustakaan Provinsi Sumtera Barat. Ilmu Informasi Perpustakaan Dan Kearsipan, 7(1), 259-269. 